\title{
The Roles of Online Instructional Facilitators and Student Performance of Online Class Activity
}

\author{
Jung Wan LEE ${ }^{1}$
}

Received: May 24, 2020 Revised: June 21, 2020 Accepted: July 03, 2020

\begin{abstract}
The study investigates the effects of online instructional facilitator's qualities on student performance of online class activities. The study explores the roles of instructional facilitators who may influence student performance of online class activities and their academic achievement. The study employs a set of aggregated data from 1,362 subjects and 10 facilitators who participated in multiple online classes. The results of independent samples t-test reveal that the student performance in online classes has no association with facilitators' educational background or academic degree, as well as demographic characteristics, student evaluation records and instructional achievement. The results of multiple regression analysis show that the facilitator engagement has a positive relation to the enhancement of student interaction, reading discussion messages, and the quality of discussion messages in online discussions. The results of correlation analysis show that the facilitator engagement has a positive impact on both increasing the number of reading discussion messages and enhancing the quality of discussion messages. The facilitator engagement increases the quantity of reading discussion postings and enhances the quality of discussion messages, which would be a substantial contribution to student performance by facilitators. The findings suggest that student performance and academic achievement in online classes are not independent of facilitator engagement.
\end{abstract}

Keywords: Instructional Facilitator, Facilitator Characteristics, Facilitator Engagement, Online Class, Online Learning, Online Discussion, Collaborative Learning

JEL Classification Code: I21, I23, I29, O30, O31

\section{Introduction}

Within the constructivist framework, there is an argument that student achievement within an online environment may be less dependent on the instructor's skill or instructional strategy, but more on student participation function. Accordingly, online discussion typically becomes the defining characteristic of an online learning environment. It is assumed that discussion forums facilitate students' learning and improve their performance in an online course through expanding the opportunity for discussion and communication among students. This assumption was usually based on the

${ }^{1}$ First Author and Corresponding Author. School of International Economics and Trade, Anhui University of Finance and Economics (AUFE), China [Postal Address: 962 Caoshan Road, Bengbu City, Anhui Province, China 233030] Email: jungwan.lee@aufe.edu.cn

(c) Copyright: The Author(s)

This is an Open Access article distributed under the terms of the Creative Commons Attribution Non-Commercial License (http://Creativecommons.org/licenses/by-nc/4.0/) which permits unrestricted noncommercial use, distribution, and reproduction in any medium, provided the original work is properly cited. idea that discussion promotes collaborative learning and the construction of shared knowledge which, in turn, facilitates better understanding of the course material and course performance.

In an online class setting, collaboration is an essential learning method. Simple in concept, but not so easy to achieve, creating an environment where discussion groups can be productive in achieving their goals is a primary role of instructional facilitators. As online facilitators, their job is to make the class and discussion easier for students and to manage the discussion like a moderator or the role of an online course instructor, which is similar to the teaching role in academic settings. Clearly, the most important functions of the online facilitator are to assist effective teaching and to accept the responsibility of keeping online discussions on track, contributing course related knowledge and insights, weaving together various discussion threads and course components, and maintaining group harmony.

There are many necessary conditions for successful online facilitation in terms of pedagogical, social, managerial, and technical, although not all of these roles 
need to be carried out in their entirety by the same person. The facilitator uses questions and probes for student responses that focus discussions on critical concepts, principles, and skills. Creating a friendly social environment in which learning is promoted is also essential for successful facilitation. It suggests that promoting human relationships, developing group cohesiveness, maintaining the group as a unit and in other ways helping members to work together in a mutual cause are all critical to a success of any online class activities. This role involves setting the agenda for the discussion: objectives, timetables, procedural rules, and decision-making norms.

In contrast to the traditional view of an instructor where students work on their own and teachers respond only when they are asked for help, the online facilitator can be seen as a person who offers guidance by using strategies such as synthesizing comments from the individual messages posted in a discussion. Bonk, Wisher and Lee (2004) stated that online facilitators should not only support interaction, but also need to know when to push individuals as well as groups further, and when to offer some useful helps to participants in constructing new knowledge. Striking a balance between supporting interaction and pushing participant inquiry, the facilitator was also described as instrumental in synthesizing distributed knowledge and guiding groups toward deeper insights (Feger \& Zibit, 2005).

Efforts to attract student participation contain a number of different paths. One typical approach focuses on the role of the online course instructor as a facilitator. For example, the course instructor encourages students to keep online discussions on track by designing good questions, providing guidelines for students when preparing their postings and responses, and providing discussion summaries. Another approach is to use instructional facilitators as an encourager which means that the facilitator encouragement would be a sufficient condition for improving participation in online discussions, for example, by providing prompt responses to initial posting messages, helping students overcome technical difficulties in the online discussion, and reinforcing the explicit expectations for student participation.

While it makes a great deal of sense theoretically, empirical demonstrations supporting the beneficial effects of discussion forum participation and the effectiveness of facilitators' instructional help are only a few. Therefore, this study focuses on expanding the dialogue on the role of instructional facilitators in enhancing student interaction and student participation in online discussions. With the instructional role in online class settings, which are becoming increasingly important, there is a need for studies that focus on the role of facilitators and how their role is developed and carried out. This study considers how facilitators foster collaborative discussions that lead to co-construction of knowledge among discussion participants by addressing the following two questions: 1) What are the roles of the facilitator in enhancing student performance in online class activity and student participation in online discussions? 2) What strategies does the facilitator use to enhance participants' performance and online class activities?

\section{Literature Review and Hypotheses}

\subsection{Online and Collaborative Learning Environments}

In collaborative learning environments, learners often created written representations collaboratively to externalize and elaborate on learning material. During this process, they created a shared external representation of the subject matter, which can be helpful for collaborative knowledge construction (Ertl, Fischer, \& Mandl, 2006). In online educational environments, common applications are frequently built as the tools for learners and offered a shared discussion forum. Such tools facilitate the active representation of knowledge and can help support learners to foster the integration of prior knowledge. However, it may be insufficient in a sense that it simply provides only a collaborative learning environment. The collaborative learning process and outcomes could be improved aggressively if appropriate additional supports were provided (Ertl et al., 2006).

In an online context, interaction is defined as the student activity of posting discussion messages and responding to others' opinions. Interaction is regarded as the most striking character of online learning formats and is considered to have one of the most significant impacts on learning outcomes in online learning environments (La Pointe \& Gunawarndena, 2004; Lavooy \& Newlin, 2003). Types of interactions can be categorized as following: (1) instructor to student, (2) facilitator to student, and (3) student to student. Among these three types of interactions, instructor to student interaction has commonly been considered the most critical one of the learning process and student learning outcomes (Mazzolini \& Maddison, 2003; Vonderwell \& Zachariah, 2005). Furthermore, the instructor's feedback and facilitation are one of the critical factors that contribute to the successful online discussions and are often cited as the catalyst for successful online learning processes (Garrison \& ClevelandInnes, 2005; Zhang, Gao, Ring, \& Zhang, 2007). The instructor will always play an important role in encouraging student participation by setting explicit expectations, such as grading strategies for participation in online discussions, which can improve the performance of students by providing necessary extrinsic motivation (Dennen, 2005).

Moreover, online discussion explores a new platform for students to give their feedback and opinions related to the course. According to Davies and Graff (2005), Rovai (2003, 2007), and Yang, Newby and Bill (2008), structured 
online discussion environments often encourage the critical thinking of the learners. Donnelly (2010) suggested that discussion forums and chat rooms are essential formats to support the social processes of learning in online learning environments. Offir, Lev, and Bezalel (2008) credited the levels of satisfaction of students for online learning environments. Although online discussions can be granted some certain advantages, such benefits can only be achieved if students are willing to participate in the discussion. However, the problem here is that although the instructorfacilitator-student interaction is considered one of the critical factors in fostering a successful online learning environment, it does not seem to occur voluntarily. Khine, Yeap, and Lok (2003) reported that students retain bad habits and do not actively participate in online discussions. Furthermore, unless feedback is required, students seem not to read others' postings nor respond to their peers (Muilenburg \& Berge, 2005). This result is reflected in an increasing focus on facilitating human interaction through online collaboration and virtual communities. In these circumstances, providing feedback to the students' posts as well as facilitating online discussions can be productive strategies for student participation in online learning environments.

Online facilitators playing the role of encourager can be an example with this matter. Online facilitator encouragement would be a sufficient condition for the increasing level of participation among postgraduate students. Hew and Cheung $(2007,2010,2011)$ and Wang (2008) indicated that peer facilitation would attract student participation better in asynchronous online discussions. Other online facilitator roles will also refer to when helping students overcome technical difficulties associated with online discussions. Guiding students to meet the expectations for participation in the online discussion (Dennen, 2005), guiding how to structure online discussions for meaningful discourse (Gilbert \& Dabbagh, 2005), and facilitating students' critical thinking in online discussions (Chiu, 2009).

According to Bento and Schuster (2003), online learning can be accomplished the most when students participate through collaboration. Hrastinski (2008) articulated how online participation can be conceptualized and summarized in six levels: 1) participation as accessing online learning systems, 2) participation as writing, 3) participation as quality writing, 4) participation as reading, 5) participation as actual writing, and 6) participation as taking part in a dialogue. Following up on his findings from the 2008 research, Hrastinski (2009) further supported the theory that online learning can be realized through student participation in online discussions. Hrastinski (2009) believed that student participation in online discussions could be a complex process of taking part in online classes and maintaining social interaction with others in the online learning environment. Morris, Finnegan, and Sz-Shyan (2005) reported that the levels of student participation in online discussions are directly related to learning outcomes, how students are perceived by their peers and instructor, and the final grades achieved from the course.

In addition, many studies informed that the asynchronous online discussion forum creates a more comfortable environment for students to engage in discussions (Cheng et al., 2011; Taradi \& Taradi, 2004; Rau, Gao, \& Wu, 2008). The support for enhanced online communication provided by discussion forums may be especially important because a better outcome of the online learning may occur as a function of the discussions. In other words, students could learn not only from the course materials and lecture notes, but also from interacting with each other and participating in discussions. Students collaboratively develop and explore hypotheses, negotiate different perspectives, and work towards common understandings. By supporting extensive interactions outside the online classroom environment, discussion forums can effectively enhance the process of acquiring, sharing and exchanging knowledge among students, thereby improving learning outcomes and performance (Cheng et al., 2011). Moreover, some researchers discovered that final achievements and overall satisfaction of students would be improved by their better performance in the online interaction section (An, Shin, \& Lim, 2009; Liu \& Tsai, 2008; Puntambekar, 2006). Therefore, asynchronous online discussion would provide better opportunities for reflective and thoughtful responses to posted discussion questions as well as insightful reactions to others' opinions and ideas (Pena-Shaff \& Nicholls, 2004).

\subsection{The Roles of Instructional Facilitators}

There is not much literature about how the role taken by the facilitator in the teaching and coaching of online degree program student interaction and learning. A wide range of evidence is used as a basis for reflection, including a detailed analysis of the online entries posted to the online discussion boards, printed records of e-mails, student results and student evaluations. It clearly emerges that facilitating in an online environment involves far more than simply transferring coaching skills from the classroom. The successful facilitator will need to learn strategies for developing online antennae, for humanizing the online learning environment, and new ways to guide students to discuss, critique and reflect together as they engage in the construction of meaning and better learning experience.

Hendrix and Degner (2016) examined facilitation experiences, demographic characteristics, and professional development activities of facilitators associated with an online program. Results showed that facilitators demographically resembled teachers but lacked similar engagement with professional development. Hylton (2007) 
compared two distinct approaches to facilitating discussions and reported that significant differences were found between student groups in the frequency and types of interactions among students as well as in learning outcomes.

Evans, Knight, Sønderlund and Tooley (2014) reported that the facilitators found positives of the experience and the flexibility of the role as a facilitator. While Evans et al. (2014) study identified positive aspects of the facilitation experience it also highlighted some key topics which need to be addressed in training for online interprofessional education facilitators to enhance their experience, and subsequently the experience and interprofessional learning of their students. Thornton and Yoong (2011) reported the role taken by the blended action learning facilitator: the two complementary aspects of this role were encouraging participation in online interactions and supporting participants in their leadership learning. Quinney and Fowler (2013) reported that facilitator involvement can enhance student learning and personal development during social work education and training. Kozar and Lum (2015) reported that online doctoral writing groups can be perceived as effective regardless of the presence of an expert facilitator and that varied in degree of facilitation and mode of communication. Becuwe, Tondeur, Roblin, Thys and Castelein (2016) reported that the perceived importance of a facilitator depends on several factors, such as team characteristics and the design phase.

Braude and Arakelian (2007) articulated the purpose of a facilitator, the qualifications necessary for a facilitator, defined the role of the facilitator and the activities of a facilitator. Williams et al. (2001) reported issues and challenges experienced by facilitators such as questioning, participation, interpersonal and group dynamics, facilitator expectations and anxieties when facilitating in a crosscultural online environment. Murphy et al. (2005) proposed a constructivist model that fosters active learning, and suggests creative ways for online instructors to manage different types of teaching responsibilities.

\subsection{Student Performance, Interaction and Participation}

Lipponen et al. (2003) illustrated that participation rates can be measured by the number of written messages and notes. Other studies also contributed to clarify the measurement of participation in number of postings to a discussion (Caspi, Chajuta, \& Saportaa, 2008; Janssen et al., 2007; Prinsen, Volman, \& Terwel, 2007). Generally, there is an accepted proposition stating that to write vociferously and frequently is proof of a more active participation in the course. However, Masters and Oberprieler (2004) argued that reading messages also provided some measures of participation, which means that students who read more messages are more likely to participate more compared to those who do not. On the contrary, Vonderwell and Zachariah (2005) stated that the level of participation could not be measured by the number of posting messages. Mazzolini and Maddison (2003) evaluated the participation rate by students and the length of the discussion threads, and stated that such outcomes provide some simplistic measurements of the interaction quality within the forum.

Furthermore, in the asynchronous online discussion, the level of engagement in discussion forums can be moderated by factors such as facilitator's involvement and possibility of receiving course credits (Taradi \& Taradi, 2004). Participation in this type of discussion forum is usually part of the course requirements; students are either given the participation credits or graded according to their level of contributions. Therefore, a more serious question is that whether the level of communication supported by online discussion forums, as indicated by both the number of posts and page access, is sufficient to promote collaborative learning and facilitate knowledge acquisition as reflected by improved academic outcomes. In other words, forum participation, defined by the number of discussion posts and times discussion are read in the discussion forum, is positively correlated with the final grades of students.

\subsection{Hypotheses}

A recent discovery examined this type of discussion forum participation, which recommended the grant of participation, and showed that the facilitator only play a passive role in the forums (Hendrix \& Degner, 2016). Nevertheless, the effect and usefulness of facilitators' instructional help in online discussions should be explored. In this circumstance, increasing the timeliness of feedback, requiring feedbacks to existing postings, and facilitating active communications would be necessary and productive strategies for facilitators to encourage student activities in online classes. These strategies are normally resulting in an increasing number of meaningful discussions. In accordance to the idea of collaborative learning, this study hypothesizes that participation in online forums would be reasonably linked to a higher level of performance in the online class activity, and it would lead to the facilitation effect since it does help improve student performance, interaction and participation. Consequently, this study proposes the following hypotheses:

H1: The number of session accessed by students is related to the role of facilitators.

H2: The number of reading discussion messages by students is related to the role of facilitators.

H3: The number of viewing content pages by students is related to the role of facilitators.

H4: The quantity of posted discussion messages by students is related to the role of facilitators. 
H5: The quality of posted discussion messages by students is related to the role of facilitators.

\section{Research Methodology}

\subsection{Participants and Data}

This study collected data from two online courses on a weekly basis for a six-week term. Data were collected from 227 graduate students in two business management courses. The class sizes of the two courses were 113 and 114 , respectively. The aggregated data of 1,362 subjects were obtained from 227 participants in online discussions for six weeks each. It must be noted that students who participated in these six-week discussions were those who were enrolled in the courses; therefore, they have been counted six times each since they participated in all six weeks of the class activity as parts of their degree programs.

Student activity data for this study were collected from the tracking report provided by the online course management system. This report provides a detailed summary of activity information for each student, including the number of accessed session, seen and posted discussion messages, and viewed content files. The grade book of the online course management system provides a numeric grade of weekly discussions and text comments of grading discussions. On one hand, the discussion board of the system provides an outline of discussion postings and indicates the number of discussion postings, the length of discussion threads, the number of interactions for each thread, and the transcripts of posted messages. On the other hand, the discussion board also provides information about the participation of group members, including the number of initiating discussion messages and follow-up discussion messages. Based on the student tracking report of the online course management system, this study used the number of posted discussion messages as the proxy of the quantity of message postings and student participation in online discussions. Instructional facilitators examined the quality of discussion messages by the grading rubric of weekly discussions provided by the lead instructor. This study used weekly discussion grades as the proxy of the quality of discussion messages and student performance in online discussions.

According to the policy of the institution, online courses require one instructor assisting up to 150 students, and need one facilitator helping every group of up to 15 students. Therefore, each class was divided into eight groups consisted of 13 to 15 students each. The instructional facilitator functioned as a moderator and grader for each group. Every facilitator was supervised by the lead instructor and in charge to complete his or her own responsibility for up to 15 students in their group.

\subsection{Measurement of Student Performance}

The student's academic capability in this paper refers to the student's ability to perform in the academic degree program and includes knowledge, skills as well as attitudes that are parts of academic competence. The student's selfacademic efficacy, the belief in their efficacy to regulate their own learning and academic attainments, in turn, contributes to their academic achievement by promoting high academic aspirations and proactive behavior. To measure the academic capability and self-academic efficacy, this study utilized the student's course grade that represents a brief sample of student's academic capability and self-academic efficacy which may be representative of the overall academic achievement. The student's course grade may range from 0 to 100 in this study.

\subsection{Control of Facilitator Engagement}

Instructional facilitators are typically provided with job descriptions, and should attend specific training programs. They are responsible for grading student academic achievement via a rubric, monitoring student performance, giving feedback on assignments, participation and their standing and progress within the course. They are usually part time or adjunct faculty, possessing at least Master's degrees in the field being taught. In addition, facilitators are provided with a five-point scale evaluation rubric and a grading policy in the course syllabus. For this study, a discussion rubric had been developed by the lead instructor to convey course expectations regarding discussions and interaction and how their participation would be evaluated. To promote students' participation in the online basis, the course was designed to account for $30 \%$ of the course grade for online discussions.

The discussion took place on a main web page where all the discussion messages were posted in discussion threads by topic. Initial entries were recorded at the head of a thread and replies/rebuttals were indented below. Each discussion thread listed the name of a student initiating a main posting, the topic, the posting date, and the number of follow-ups. This is because the discussion board provides an asynchronous text-based environment, and the students had opportunities to articulate their thoughts regarding the assigned readings as well as their responses on other students' ideas. They could participate as many times as they wish, but they were required one initial posting and two follow-up postings in a single week base.

Collaboration and dialogue were encouraged by grading weekly discussions and the engagement of facilitators. The engagement of facilitators in weekly discussions was used as the control variable for this study. Four out of eight discussion groups of each course were used as the experimental groups. These four experimental groups received facilitator 
engagement wherein the lead instructor asked the facilitators to actively engage in facilitating student participation in online discussions by sending emails, providing feedback, and responding postings. In addition, the remaining four groups were considered as the control groups in which they did not receive any facilitator engagement, the lead instructor has played a limited role to facilitate student participation in online discussions and the assigned facilitators for these four groups merely played their role as the grader of weekly discussions.

Table 1 reports the descriptive statistics of facilitator characteristics and evaluation scores by students. Table 2 reports the results of ANOVA of student performance of class activity by facilitator group.

Table 1: Descriptive statistics of facilitator characteristics and evaluation scores by students

\begin{tabular}{|l|c|c|c|c|c|}
\hline \multicolumn{1}{|c|}{ Facilitator Pool } & $\begin{array}{c}\text { Number of } \\
\text { Students }\end{array}$ & Percent & $\begin{array}{c}\text { Student Evaluation } \\
\text { for Facilitator (of 5) }\end{array}$ & $\begin{array}{c}\text { Facilitator } \\
\text { Education } \\
\text { Background }\end{array}$ & $\begin{array}{c}\text { Facilitator } \\
\text { Demographics }\end{array}$ \\
\hline Facilitator A & 78 & 11.1 & 4.88 & Doctorate & Male \\
\hline Facilitator B & 67 & 9.6 & 4.85 & Doctorate & Female \\
\hline Facilitator C & 37 & 5.3 & 4.81 & Doctorate & Female \\
\hline Facilitator D & 94 & 13.4 & 4.55 & Master & Male \\
\hline Facilitator E & 53 & 7.6 & 4.46 & Master & Male \\
\hline Facilitator F & 22 & 3.1 & 4.46 & Master & Male \\
\hline Facilitator G & 92 & 13.1 & 4.15 & Master & Male \\
\hline Facilitator H & 96 & 13.7 & 4.05 & Master & Female \\
\hline Facilitator I & 76 & 10.9 & 3.88 & Master & Male \\
\hline Facilitator J & 85 & 12.1 & 3.65 & Master & Female \\
\hline Total & 700 & 100.0 & & & \\
\hline
\end{tabular}

Table 2: Results of ANOVA of student performance of class activity by facilitator group

\begin{tabular}{|c|c|c|c|c|c|c|}
\hline \multicolumn{2}{|c|}{$\begin{array}{c}\text { Student Performance } \\
\text { of Class Activity }\end{array}$} & Sum of Squares & df & Mean Square & $\mathbf{F}$ & Sig. \\
\hline \multirow{3}{*}{$\begin{array}{l}\text { Online } \\
\text { Discussion } \\
(30 \%)\end{array}$} & Between Groups & 235.150 & 9 & 26.128 & 8.590 & .000 \\
\hline & Within Groups & 2098.729 & 690 & 3.042 & & \\
\hline & Total & 2333.878 & 699 & & & \\
\hline \multirow{3}{*}{$\begin{array}{l}\text { Essay } \\
(10 \%)\end{array}$} & Between Groups & 15.736 & 9 & 1.748 & 4.235 & .000 \\
\hline & Within Groups & 284.886 & 690 & .413 & & \\
\hline & Total & 300.622 & 699 & & & \\
\hline \multirow{3}{*}{$\begin{array}{l}\text { Team Project } \\
(30 \%)\end{array}$} & Between Groups & 46.528 & 9 & 5.170 & 4.158 & .000 \\
\hline & Within Groups & 857.931 & 690 & 1.243 & & \\
\hline & Total & 904.458 & 699 & & & \\
\hline \multirow{3}{*}{$\begin{array}{l}\text { Exam } \\
(30 \%)\end{array}$} & Between Groups & 58.019 & 9 & 6.447 & 1.195 & .295 \\
\hline & Within Groups & 3723.327 & 690 & 5.396 & & \\
\hline & Total & 3781.347 & 699 & & & \\
\hline \multirow{3}{*}{$\begin{array}{l}\text { Final Grade } \\
\text { (Total 100) }\end{array}$} & Between Groups & 665.197 & 9 & 73.911 & 4.975 & .000 \\
\hline & Within Groups & 10251.288 & 690 & 14.857 & & \\
\hline & Total & 10916.485 & 699 & & & \\
\hline
\end{tabular}




\section{Empirical Results}

\subsection{Independent Samples T-Test and ANOVA}

Table 3 reports the results of independent samples t-test of the relationship between student performance of class activity and facilitator education background. Table 4 reports the results of independent samples t-test of the relationship between student performance of class activity and facilitator demographics. Table 5 reports the results of ANOVA of the relationship between student performance of class activity and facilitator evaluation by students.

\subsection{Multivariate Regression}

Table 6 indicates that results of the multiple regression analysis. The results show that the hypothesis 1, 3, 4 are not supported by the multiple regression analysis, but the hypothesis 2 and 5 are supported by the analysis. The results suggest that the number of session accesses by students, the number of content view, and the number of posted discussion messages are not significantly related to the role of facilitators.

Hypothesis 2 and 5 are supported by the results of the multiple regression analysis, which means that both the quantity of reading discussion messages and the quality of discussion messages are related to the role of facilitators. At the same time, the results of correlation analysis show that the facilitator engagement has a positive impact on increasing the number of reading discussion messages and enhancing the quality of discussion messages. Consequently, there is a significant difference between the quantity of reading discussion messages and the quality of discussion messages in online discussions when facilitators are engaged with such a matter. The facilitator engagement increases the quantity of reading discussion messages, even though it

Table 3: Results of the relationship between student performance and facilitator education background

\begin{tabular}{|c|c|c|c|c|c|c|}
\hline \multicolumn{2}{|c|}{$\begin{array}{c}\text { Student Performance } \\
\text { of Class Activity }\end{array}$} & \multirow{2}{*}{$\begin{array}{c}\text { F-statistic }^{1} \\
9.581\end{array}$} & \multirow{2}{*}{$\begin{array}{l}\text { Sig. } \\
.002\end{array}$} & \multirow{2}{*}{$\begin{array}{c}\text { t-statistic } \\
-2.586\end{array}$} & \multirow{2}{*}{$\begin{array}{c}\text { df } \\
698 \\
\end{array}$} & \multirow{2}{*}{$\begin{array}{c}\begin{array}{c}\text { Sig. } \\
\text { (2-tailed) }\end{array} \\
.010\end{array}$} \\
\hline Online Discussion & Equal variances assumed & & & & & \\
\hline$(30 \%)$ & Equal variances not assumed & & & -2.089 & 232.710 & .038 \\
\hline \multirow{2}{*}{$\begin{array}{l}\text { Assignment1 } \\
\text { (Essay) }(10 \%)\end{array}$} & Equal variances assumed & .005 & .941 & -2.164 & 698 & .031 \\
\hline & Equal variances not assumed & & & -2.616 & 479.588 & .009 \\
\hline \multirow{2}{*}{$\begin{array}{l}\text { Assignment2 } \\
\text { (Team project) (30\%) }\end{array}$} & Equal variances assumed & 6.046 & .014 & 1.819 & 698 & .069 \\
\hline & Equal variances not assumed & & & 2.009 & 387.035 & .045 \\
\hline \multirow{2}{*}{$\begin{array}{l}\text { Final Grade } \\
\text { (Total } 100)\end{array}$} & Equal variances assumed & .000 & .988 & -1.245 & 698 & .214 \\
\hline & Equal variances not assumed & & & -1.202 & 298.123 & .230 \\
\hline
\end{tabular}

${ }^{1}$ Levene's test for equality of variances

${ }^{2}$ t-test for equality of means

Table 4: Results of the relationship between student performance and facilitator demographics

\begin{tabular}{|c|c|c|c|c|c|c|}
\hline \multicolumn{2}{|c|}{$\begin{array}{c}\text { Student Performance } \\
\text { of Class Activity }\end{array}$} & F-statistic ${ }^{1}$ & Sig. & t-statistic ${ }^{2}$ & df & $\begin{array}{c}\text { Sig. } \\
\text { (2-tailed) }\end{array}$ \\
\hline \multirow{2}{*}{$\begin{array}{l}\text { Weekly } \\
\text { Discussion (30\%) }\end{array}$} & Equal variances assumed & 2.813 & .094 & .917 & 698 & .359 \\
\hline & Equal variances not assumed & & & .901 & 571 & .368 \\
\hline \multirow{2}{*}{$\begin{array}{l}\text { Assignment1 } \\
\text { (Essay) }(10 \%)\end{array}$} & Equal variances assumed & 1.237 & .266 & -.241 & 698 & .810 \\
\hline & Equal variances not assumed & & & -.233 & 535 & .816 \\
\hline \multirow{2}{*}{$\begin{array}{l}\text { Assignment2 } \\
\text { (Team Project) (30\%) }\end{array}$} & Equal variances assumed & .299 & .585 & -1.267 & 698 & .206 \\
\hline & Equal variances not assumed & & & -1.273 & 620 & .203 \\
\hline \multirow{2}{*}{$\begin{array}{l}\text { Final Grade } \\
\text { (Total 100) }\end{array}$} & Equal variances assumed & .207 & .650 & .711 & 698 & .477 \\
\hline & Equal variances not assumed & & & .712 & 614 & .476 \\
\hline
\end{tabular}

${ }^{1}$ Levene's test for equality of variances

2 t-test for equality of means 
Table 5: Results of ANOVA of student performance and facilitator evaluation by students

\begin{tabular}{|c|c|c|c|c|c|c|}
\hline \multicolumn{2}{|c|}{$\begin{array}{l}\text { Student Performance } \\
\text { of Class Activity }\end{array}$} & Sum of Squares & df & Mean Square & $\mathbf{F}$ & Sig. \\
\hline \multirow{3}{*}{$\begin{array}{l}\text { Online } \\
\text { Discussion } \\
(30 \%)\end{array}$} & Between Groups & 22.96 & 2 & 11.48 & 3.463 & .032 \\
\hline & Within Groups & 2310.91 & 697 & 3.31 & & \\
\hline & Total & 2333.87 & 699 & & & \\
\hline \multirow{3}{*}{$\begin{array}{l}\text { Assignment1 } \\
\text { (Essay) } \\
(10 \%)\end{array}$} & Between Groups & 4.60 & 2 & 2.30 & 5.420 & .005 \\
\hline & Within Groups & 296.01 & 697 & .42 & & \\
\hline & Total & 300.62 & 699 & & & \\
\hline \multirow{3}{*}{$\begin{array}{l}\text { Assignment2 } \\
\text { (Team Project) } \\
(30 \%)\end{array}$} & Between Groups & 8.96 & 2 & 4.48 & 3.488 & .031 \\
\hline & Within Groups & 895.49 & 697 & 1.28 & & \\
\hline & Total & 904.45 & 699 & & & \\
\hline \multirow{3}{*}{$\begin{array}{l}\text { Final Grade } \\
\text { (Total 100) }\end{array}$} & Between Groups & 53.93 & 2 & 26.96 & 1.730 & .178 \\
\hline & Within Groups & 10862.54 & 697 & 15.58 & & \\
\hline & Total & 10916.48 & 699 & & & \\
\hline
\end{tabular}

Table 6: Results of regression analysis of student performance and facilitator engagement

\begin{tabular}{|l|c|c|c|}
\hline \multicolumn{1}{|c|}{ Model } & B & Std. Error & t-statistic \\
\hline H1: Session Access & -0.135 & 0.137 & -.985 \\
\hline H2: Reading Discussion Messages & 1.155 & 0.052 & $22.144^{* * *}$ \\
\hline H3: Viewing Content & 0.188 & 0.144 & 1.305 \\
\hline H4: Quantity of Discussion Messages & 0.143 & 0.138 & 1.036 \\
\hline H5: Quality of Discussion Messages & 1.161 & 0.083 & $14.051^{* * *}$ \\
\hline Constant & 10.303 & 2.221 & 4.640 \\
\hline
\end{tabular}

Dependent Variable: Final Grade

R-square $=0.667$ Adjusted R-square $=0.665$ ANOVA F-statistic $=348.343$

Probability values for rejection of the null hypothesis are employed at the 0.05 level (***, p-value $<0.01$ ).

would be a nominal increase, and the quality of discussion messages which is a substantial contribution to student performance by facilitators. The results suggest that the student performance and academic achievement in online classes are not independent of the facilitator's engagement. Therefore, the facilitator engagement in online discussions positively influences an enhancement of the quality of discussion messages.

\section{Discussion and Instructional Implications}

According to the results, the quantity of reading discussion message and the quality of discussion messages in online discussions are not independent of facilitator engagement. The results of this study provide strong evidence that the facilitator engagement enhances student performance in online class activities. This study also finds that the facilitator engagement positively influences an enhancement of the quality of discussion messages, although its impact on students can vary on an individual basis. When the data is grouped in accordance with the facilitator engagement, the student class activity shows a significant difference in terms of the quantity of reading discussion messages and the quality of posted discussion messages. For this reason, the facilitator engagement can be an effective method, which would help increase student performance and interaction and participation in online classes. Findings from this research suggest that students would benefit from posting high quality of discussion messages, and the degree of interaction and participation can be greatly enhanced by the facilitator engagement.

Possible applications of findings of the study are presented as follows. First, using trained facilitators can promote student interaction and participation in online 
discussions and enhance student performance in online class activities. Facilitation techniques include facilitator engagement through sharing experiences and knowledge, questioning, showing appreciation, suggesting new directions, and/or inviting students to make more timely and valuable contributions. As a result, the facilitator engagement significantly promotes student interaction and participation in online discussions. Second, providing guidelines and grading rubrics can increase student interaction and participation in online class activities. Although some students will have the necessary intrinsic motivation to engage in productive discussions at the beginning of online classes, others may not. In consequence, instructional facilitators must provide a measure of the extrinsic motivation for students to actively participate in online class activities. After providing such motivation, the result showed that there has been a significant increase in the number of posting discussion messages per week. Obviously, the goal is to create a collaborative learning environment which motivates students to engage actively in online social interaction and online discussions.

This paper highlights the importance of the roles of instructional facilitators in encouraging student interaction and participation in online class activities. As a result, the following principles applicable to the roles of facilitators in online classes are identified. First, the facilitator should collect direct evidence of students' contribution and assess their performance according to a well-established criteria. To make it success, the facilitator should be provided with the course assessment policy and applicable standard criteria for assessment in order to minimize the facilitator's subjective reflection on the assessment process. Second, the facilitator should maximize students' interaction and participation. In discussion groups, every participant is an expert within his or her own context, and has valuable input. Facilitators should create a safe environment that enables students to speak honestly as well as considering feelings of others. In order to achieve this objective, facilitators often spend considerable time helping participants from interactions with one another.

The facilitator pushes participants to identify critical factors and to articulate, and then justify ways of thinking. Therefore, the facilitator will be acting like a coach, observing participants while they are carrying out a task and offering hints, scaffolding, giving feedback, modeling, prompting with reminders, and sending out new tasks aimed at bringing their performance closer to expert performance. The facilitator's explanation of methods include the followings: pushing participants to extend their thinking, asking for evidence of understanding, framing a question to raise an idea that is worth revisiting, and suggesting further exploration by asking. In reflecting on the role, the facilitator notes how it is a complicated dance of knowing when and how to ask questions or to give guidance, and this is a critical characteristic of the steering strategy. Steering with the best knowledge in the sense of coaching is a method that helps participants attune their skills and understanding whether in relation to comments from others, reflections about student work, a participant's own classroom experiences, or the larger context of the online learning environment.

A strategy of steering toward others encourages participants to share and learn from each other and to develop a common repertoire of knowledge and specific ways of addressing similar problems and purposes. There are many comments from participants about what made weekly online discussions useful for their studies related to the sense of online community. These include: being part of a group of colleagues who have similar interests; and referencing how others handle common situations based on their own experience is probably considered the most valuable aspect of weekly online discussions. The matter supported the steering toward others a unique and useful strategy is that it fosters the development of a course related knowledge base within an online learning community. The strategy made it possible for a diverse group of students evolving into an online learning community where participants actively engaged in sharing ideas while furthering their own learning and advancing the collective knowledge of the group simultaneously.

A potential limitation of this study turned out that the findings were primarily drawn upon the number of students' discussion postings and the level of student performance. By doing so, a student's contribution, interaction and participation was measured based upon the quantity of posted discussion messages, while the student performance and academic achievement is measured by their GPA. With acknowledging the limitation of this approach, this study calls for future research to elaborate a standard that would turn itself into the better measurements of student performance and online interaction and participation in online class activities.

\section{References}

An, H.J., Shin, S.H., \& Lim, K.O. (2009). The effects of different instructor facilitation approaches on students' interactions during asynchronous online discussions. Computers \& Education, 53(3), 749-760

Becuwe, H., Tondeur, J., Roblin, N.P., Thys, J., \& Castelein, E. (2016). Teacher design teams as a strategy for professional development: the role of the facilitator. Educational Research and Evaluation, 22(3-4), 141-154. http://dx.doi.org/10.1080/13 803611.2016.1247724

Bento, R., \& Schuster, C. (2003). Participation: The online challenge. In: A. Aggarwal (ed.), Web-based education: Learning from experience (pp. 156-164). Hershey, PA: Idea Group Publishing. 
Bonk, C., Wisher, R. A., \& Lee, J. Y. (2004). Moderating learnercentered e-learning: Problems and solutions, benefits and implications. In T. S. Roberts (Ed.), Online collaborative learning: Theory and practice (pp. 54-85). Hershey, PA: Information Science Publishing.

Braude, E., \& Arakelian, A. (2007). Facilitating security education in an online environment. Journal of Security Education, 2(3), 33-40. http://dx.doi.org/10.1300/J460v02n03_03

Caspi, A., Chajuta, E., \& Saportaa, K. (2008). Participation in class and in online discussions: Gender differences. Computers \& Education, 50(3), 718-724.

Cheng, C. K., Paré, D.E., Collimore, L.-M., \& Joordens, S. (2011). Assessing the effectiveness of a voluntary online discussion forum on improving students' course performance. Computers \& Education, 56(1), 253-261.

Chiu, Y.-C. J. (2009). Facilitating Asian students' critical thinking in online discussions. British Journal of Educational Technology, $40(1), 42-57$.

Davies, J., \& Graff, M. (2005). Performance in e-learning: Online participation and student grades. British Journal of Educational Technology, 36(4), 657-663.

Dennen, V.P. (2005). From message posting to learning dialogues: Factors affecting learner participation in asynchronous discussion. Distance Education, 26(1), 127-148.

Donnelly, R. (2010). Harmonizing technology with interaction in blended problem-based learning. Computers \& Education, 54(2), 350-359

Ertl, B., Fischer, F., \& Mandl, H. (2006). Conceptual and socio-cognitive support for collaborative learning in videoconferencing environments. Computers \& Education, 47, 298-315.

Evans, S., Knight, T., Sønderlund, A., \& Tooley, G. (2014). Facilitators' experience of delivering asynchronous and synchronous online interprofessional education. Medical Teacher, 36(12), 1051-1056. http://dx.doi.org/10.3109/014215 9X.2014.918254

Feger, S. \& Zibit, M. (2005). The role of facilitation in online professional development: Engendering co-construction of knowledge. Providence, RI: The Education Alliance at Brown University.

Garrison, D.R., \& Cleveland-Innes, M. (2005). Facilitation cognitive presence in online learning: Interaction is not enough. The American Journal of Distance Education, 19(3), 133-148.

Gilbert, P. K. \& Dabbagh, N. (2005). How to structure online discussions for meaningful discourse: a case study. British Journal of Educational Technology, 36(1), 5-18.

Hendrix, N., \& Degner, K. (2016). Supporting online AP students: The rural facilitator and considerations for training. American Journal of Distance Education, 30(3), 133-144. http://dx.doi.or g/10.1080/08923647.2016.1198194

Hew, K. F. \& Cheung, W. S. (2007). Attracting student participation in asynchronous online discussions: A case study of peer facilitation. Computers \& Education, 51, 1111-1124.
Hew, K. F. \& Cheung, W.S. (2010). Possible factors influencing Asian students' degree of participation in peer-facilitated online discussion forums: a case study. Asia Pacific Journal of Education, 30(1), 85-104.

Hew, K. F. \& Cheung, W.S. (2011). Student facilitators' habits of mind and their influences on higher-level knowledge construction occurrences in online discussions: a case study. Innovations in Education and Teaching International, 48(3), 275-285.

Hrastinski, S. (2008). What is online learner participation? A literature review. Computers \& Education, 51(4), 1755-1765.

Hrastinski, S. (2009). A theory of online learning as online participation. Computers \& Education, 52(1), 78-82.

Hylton, M.E. (2007). Facilitating online learning communities: a comparison of two discussion facilitation techniques. Journal of Technology in Human Services, 25(4), 63-78. http://dx.doi. org/10.1300/J017v25n04_04

Janssen, J., Erkensa, G., Kanselaara, G., \& Jaspersa, J. (2007). Visualization of participation: Does it contribute to successful computer-supported collaborative learning? Computers \& Education, 49(4), 1037-1065.

Khine, M., Yeap, L., \& Lok, A. (2003). The quality of message ideas. Thinking and interaction in an asynchronous CMC environment. Educational Media International, 40(1-2), 115-125.

Kozar, O., \& Lum, J.F. (2015). Online doctoral writing groups: do facilitators or communication modes make a difference? Quality in Higher Education, 21(1), 38-51. http://dx.doi.org/10 $.1080 / 13538322.2015 .1032003$

La Pointe, K.D., \& Gunawarndena, C. (2004). Developing testing and refining of a model to understand the relationship between peer interaction and learning outcomes in computer-mediated conferencing. Distance Education, 25(1), 93-106.

Lavooy, M.J., \& Newlin, M.H. (2003). Computer mediated communication: Online instruction and interactivity. Journal of Interactive Learning Research, 14(2), 157-165.

Lipponen, L., Rahikainen, M., Lallimo, J., \& Hakkarainen, K. (2003). Patterns of participation and discourse in elementary students' computer-supported collaborative learning. Learning and Instruction, 13(5), 487-509.

Liu, C.C., \& Tsai, C.C. (2008). An analysis of peer interaction patterns as discoursed by online small group problem-solving activity. Computers \& Education, 50(3), 627-639

Masters, K., \& Oberprieler, G. (2004). Encouraging equitable online participation through curriculum articulation. Computers \& Education, 42(4), 319-332.

Mazzolini, M., \& Maddison, S. (2003). Sage, guide or ghost? The effect of instructor intervention on student participation in online discussion forums. Computers \& Education, 40(3), 237-253.

Morris, K.V., Finnegan, C., \& Sz-Shyan, W. (2005). Tracking student behavior, persistence, and achievement in online courses. Internet and Higher Education, 8(3), 221-231. 
Muilenburg, L.Y., \& Berge, Z.L. (2005). Student barriers to online learning: A factor analytic study. Distance Learning, 26(1), $29-48$.

Murphy, K.L., Mahoney, S.E., Chen, C., Mendoza-Diaz, N.V., \& Yang, X.(2005).AConstructivist Model of Mentoring, Coaching, and Facilitating Online Discussions. Distance Education, 26(3), 341-366. http://dx.doi.org/10.1080/01587910500291454

Offir, B., Lev, Y., \& Bezalel, R. (2008). Surface and deep learning processes in distance education: Synchronous versus asynchronous systems. Computers \& Education, 51(3), 1172-1183

Pena-Shaff, J.B., \& Nicholls, C. (2004). Analyzing student interactions and meaning construction in computer bulletin board discussions. Computers \& Education, 42(3), 243-265

Prinsen, F., Volman, M.L.L., \& Terwel, J. (2007). The influence of learner characteristics on degree and type of participation in a CSCL environment. British Journal of Educational Technology, 38(6), 1037-1055.

Puntambekar, S. (2006). Analyzing collaborative interactions: divergence, shared understanding and construction of knowledge. Computers \& Education, 47(3), 332-351

Quinney, L., \& Fowler, P. (2013). Facilitating shared online group learning between careers, service users and social work students. Social Work Education, 32(8), 1021-1031. http:// dx.doi.org/10.1080/02615479.2012.734801

Rau, P. L. P., Gao, Q., \& Wu, L. M. (2008). Using mobile communication technology in high school education: motivation, pressure, and learning performance. Computers \& Education, 50(1), 1-22.

Rovai, A.P. (2003). Strategies for grading online discussions: Effects of discussions and classroom community in Internet- based university courses. Journal of Computing in Higher Education, 15(1), 89-107.

Rovai, A.P. (2007). Facilitating online discussions effectively. Internet and Higher Education, 10(1), 77-88.

Taradi, S. K., \& Taradi, M. (2004). Expanding the traditional physiology class with asynchronous online discussions and collaborative projects. Advances in Physiology Education, 28(2), 73-78.

Thornton, K., \& Yoong, P. (2011). The role of the blended action learning facilitator: an enabler of learning and a trusted inquisitor. Action Learning: Research and Practice, 8(2), 129-146.

Vonderwell, S., \& Zachariah, S. (2005). Factors that influence participation in online learning. Journal of Research on Technology in Education, 38(2), 213-230.

Wang, Q. (2008). Student-facilitators' roles in moderating online discussions. British Journal of Educational Technology, 39(5), 859-874.

Williams, S.W., Watkins, K., Daley, B., Courtenay, B., Davis, M., \& Dymock, D. (2001). Facilitating cross-cultural online discussion groups: Implications for practice. Distance Education, 22(1), 151-167. http://dx.doi.org/10.1080/0158791010220110

Yang, Y.T.C., Newby, T., \& Bill, R. (2008). Facilitating interactions through structured web-based bulletin boards: A quasiexperimental study on promoting learners' critical thinking skills. Computers \& Education, 50(4), 1572-1585.

Zhang, T., Gao, T., Ring, G., \& Zhang, W. (2007). Using online discussion forums to assist a traditional English class. International Journal of E-Learning, 6(4), 623-643. 